\title{
The Influence of $3 d$ and $4 d$ Transition Metals on the Glass Forming Ability of Ternary FeCo-Based Alloys
}

\author{
Z. ŚNIADECKI
}

Thermodynamic modeling was used to determine enthalpies of formation and other thermodynamic parameters describing glass forming ability of Fe-Co-TM $(\mathrm{TM}=\mathrm{V}, \mathrm{Nb}, \mathrm{Cr}, \mathrm{Mo})$ alloys. FeCo-based alloys are considered as candidates for applications as high magnetic flux density materials due to their high magnetic saturation and low magnetic anisotropy. Nevertheless, mechanical properties, especially the lack of ductility, are their main weakness. Therefore, further optimization by vitrification, further heat treatment and alloying should be considered. As the most crucial step is the synthesis of amorphous precursors, discussion is concentrated on the effect of transition metal substitution on the glass forming ability. The highest glass forming ability was reported for Fe-Co-Nb alloys. It can be also noted that the driving force for vitrification can be improved by substitution of $\mathrm{Fe}$ by other transition elements, as glass forming ability parameter $\Delta P_{H S}$ reaches the lowest values for Fe-less compositions.

https://doi.org/10.1007/s11661-021-06196-7

(C) The Author(s) 2021

\section{INTRODUCTION}

WELL-KNOWN FeCo-based alloys, which crystallize in bcc structure (called Permendur), possess high magnetic saturation of about $2.4 \mathrm{~T}$. In combination with their low magnetic anisotropy, these materials are of interest for electrotechnical industry, where high magnetic flux density is needed (e.g., generators), even considering slightly increased cost due to high Co content. ${ }^{[1]}$ Their properties, also mechanical, can be further improved by alloying, with Hiperco as one of the examples. ${ }^{[2]}$ Further improvement of deformability or fracture strength with subsequent optimization of resistivity and coercivity is connected with vitrification. ${ }^{[3-5]}$ FeCo-based amorphous alloys can be synthesized by typical physical methods utilizing quenching of molten alloy or by sputtering. ${ }^{[3,6]} \mathrm{FeCo}$ alloy is a poor glass former, therefore glass forming ability (GFA) have to be improved by addition of other elements such as $\mathrm{B}, \mathrm{Si}$, or other transition metals, as for example $\mathrm{Zr}$ or $\mathrm{Ta}^{\left[{ }^{[7-9]}\right.}$ Amorphous particles, also pure FeCo alloys, were also prepared by chemical methods through chemical reduction of metal ions with $\mathrm{KBH}_{4}$ and $\mathrm{NaBH}_{4}$ in aqueous solution. ${ }^{[10,11]}$ Although such materials are promising candidates as energy harvesters ${ }^{[12]}$ or even in medical

Z. SNIADECKI is with the Institute of Molecular Physics, Polish Academy of Sciences, M. Smoluchowskiego 17, 60-179 Poznan, Poland. Contact e-mail: sniadecki@ifmpan.poznan.pl

Manuscript submitted June 22, 2020; accepted February 10, 2021.

Article published online March 11, 2021 applications, ${ }^{[13]}$ one should bear in mind that the addition of any non-magnetic element or even contaminations in chemical methods deteriorate their unique magnetic properties. Therefore, the general aim of studies should be focused on the synthesis of possibly pure FeCo-based alloys. It is intended to use sputtering method to obtain fully amorphous films and to determine the influence of homogeneity of amorphous structure on soft magnetic and mechanical properties. Variation of sputtering conditions will be utilized to form amorphous thin films with various packing density and even samples with inhomogeneous morphology (so-called nanoglasses ${ }^{[14,15]}$ ). Regarding mechanical properties it is believed that in the case of nanoglasses one should observe an improvement in hardness and Young's modulus compared to the melt-spun ribbons. Homogeneous deformation is observed as interfaces with high free volume promote the nucleation of many shear transformation zones. ${ }^{[16]}$ Such amorphous alloys can be used in the next step as precursors in formation of nanocrystalline systems, what can result in further improvement of desirable properties mentioned above. The results presented in this paper, where formation enthalpies were determined for Fe-Co-TM $(\mathrm{TM}=\mathrm{V}$, $\mathrm{Cr}, \mathrm{Nb}, \mathrm{Mo}$ ) system, can serve as a roadmap for further development of amorphous films with specific structure and morphology. The GFA reflects the tendency for amorphous state formation and can be determined both experimentally and theoretically. ${ }^{[17,18]}$ Thermodynamic model (semi-empirical Miedema's model $)^{[19-21]}$ is utilized here to determine glass forming abilities. 
Compositions with higher GFA will be beneficial while utilizing their broad energy landscape of amorphous state stability to form glassy samples with various short/ medium range order and morphology. Presented results are the extension of previous studies undertaken for Fe-Ni-based systems. ${ }^{[22]}$

\section{CALCULATIONS}

GFA was estimated on the basis of the semi-empirical Miedema's model, ${ }^{[1,20]}$ through calculations of various quantities, as enthalpy of formation of amorphous phase $\Delta H^{\mathrm{am}}$, normalized mismatch entropy $S_{\sigma} / k_{\mathrm{B}}{ }^{[23]}$ and GFA parameter $\Delta P_{H S}$.

Atoms in the utilized model ${ }^{[19]}$ are represented by blocks with the Wigner-Seitz cell boundaries. Changes of enthalpy are calculated for virtual process of alloying of A element atoms in a matrix of B atoms. There are three basic quantities which govern this process: (i) molar volume $V$, (ii) potential $\varphi$ and (iii) density at the boundary of Wigner-Seitz cell $n_{w s}$. Interfacial enthalpy $\Delta H^{\text {inter }}(\mathrm{A}$ in $\mathrm{B})$ defined as

$$
\Delta H^{\text {inter }}(\mathrm{A} \text { in } \mathrm{B})=\frac{V_{\mathrm{A}}^{2 / 3}}{\frac{1}{2}\left(\frac{1}{n_{w s A}^{1 / 3}}+\frac{1}{n_{w s B}^{1 / 3}}\right)}\left\{-P(\Delta \varphi)^{2}+Q\left(\Delta n_{w s}^{1 / 3}\right)^{2}\right\} \text {, }
$$

where $P$ and $Q$ are empirical proportionality constants dependent on alloying elements, expresses the process of solving one mole of $\mathrm{A}$ atoms in an excess of $\mathrm{B}$ atoms. Chemical enthalpy $\Delta H^{\text {chem }}$ can be then calculated for binary alloy using following equation:

$$
\Delta H^{\text {chem }}=c_{\mathrm{A}} c_{\mathrm{B}}\left(c_{\mathrm{B}}^{s} \Delta H^{\text {inter }}(A \text { in } B)+c_{\mathrm{A}}^{s} \Delta H^{\text {inter }}(B \text { in } A)\right),
$$

where $c_{\mathrm{A}}$ and $c_{\mathrm{B}}$ are volume fractions of $\mathrm{A}$ and $\mathrm{B}$ atoms, while $c_{\mathrm{A}}^{\mathrm{s}}$ and $c_{\mathrm{A}}^{\mathrm{s}}$ are their surface fractions. The formation enthalpy of the amorphous phase can be determined using chemical and topological contributions, where the later one reflects disorder in the amorphous state.

Formation enthalpy of solid solutions was also calculated as a reference (see Appendix, Figure A1). It depends on the chemical enthalpy, elastic enthalpy $\Delta H^{\text {elast }}$ connected with atomic size mismatch, and the structural one $\Delta H^{\text {struct }}$ originating from valence and crystal structure. Structural term was not taken into account in the analysis due to reasons elucidated in the Results and Discussion section. Differences of enthalpies of amorphous phase and a solid solution formation, $\Delta H^{\mathrm{am}-\mathrm{ss}}=\Delta H^{\mathrm{am}}-\Delta H^{\mathrm{ss}}$, are also presented in the Appendix (Figure A2).

Normalized mismatch entropy and GFA parameter were calculated for each composition. $S_{\sigma} / k_{\mathrm{B}}$ is connected with atomic radius mismatch of the constituent elements, while $\Delta P_{H S}$ is the product of chemical enthalpy $\Delta H^{\text {chem }}$ and mismatch entropy. ${ }^{[18]}$ The thermodynamic properties of sub-binaries were extrapolated to ternaries with the use of geometric model. ${ }^{[24-26]}$ All contour maps were calculated with composition changing with 1 at. pct step. Methods described above are delineated in more details in Reference 21.

\section{RESULTS AND DISCUSSION}

GFA of Fe-Co-TM (TM = V, Cr, Nb, Mo) systems was evaluated at first by determination of formation enthalpy of amorphous phase. Particular substituting elements were chosen as representatives of $3 d$ and $4 d$ transition metals, to make direct comparison with previously published results for Fe-Ni-TM systems. ${ }^{[22]}$ Composition dependences of $\Delta H^{\text {am }}$ are shown in Figure 1 for all TM substitutions. Negative values of formation enthalpy, which indicate possibility to form amorphous state, were obtained for elements from group $\mathrm{V}$ in the periodic table, namely $\mathrm{V}$ and $\mathrm{Nb}$. The most negative enthalpies of formation were determined for $\mathrm{Nb}-\mathrm{Co}$ binary alloys near equiatomic composition $\left(\Delta H^{\mathrm{am}}=-16.7 \mathrm{~kJ} / \mathrm{mol}\right.$ for $\left.\mathrm{Co}_{55} \mathrm{Nb}_{45}\right)$. Niobium is preferred mainly due to its large negative values of interfacial enthalpy with other constituents $\left(\Delta H^{\text {inter }}(\mathrm{Fe}\right.$ in $\mathrm{Nb})=-57 \mathrm{~kJ} / \mathrm{mol}, \Delta H^{\text {inter }}(\mathrm{Nb}$ in $\mathrm{Fe})$ $=-70 \mathrm{~kJ} / \mathrm{mol}, \Delta H^{\text {inter }}(\mathrm{Co}$ in $\mathrm{Nb})=-88 \mathrm{~kJ} / \mathrm{mol}$, $\Delta H^{\text {inter }}(\mathrm{Nb}$ in $\left.\mathrm{Co})=-111 \mathrm{~kJ} / \mathrm{mol}\right)$. One can notice qualitative agreement between $\Delta H^{\mathrm{am}}$ contour maps for $\mathrm{Nb}$ and $\mathrm{V}$ substitutions. Both elements are from group $\mathrm{V}$ of periodic table and the values of their interfacial enthalpies with other constituents, their molar volumes $V$, potentials $\varphi$, and electronic densities at the boundary of Wigner-Seitz cell $n_{w s}$ are similar in contrast to group VI elements ( $\mathrm{Cr}$ and Mo). For group VI elements, $\Delta H^{\mathrm{am}}$ has positive values with limited range of variation and reaches maxima in the vicinity of $\mathrm{Cr}$-rich and Mo-rich corners. All conclusions drawn on the basis of $\Delta H^{\mathrm{am}}$ phase diagrams converge with previous results on Ni-containing systems. ${ }^{[22]}$

Enthalpies of formation of solid solution $\Delta H^{\mathrm{ss}}$ were also calculated (Figure A1 in Appendix). Solid solutions are assumed to play a role of thermodynamically stable counterparts. The aim was to qualitatively compare them with amorphous phases to mimic real competition during solidification process. Chemical and elastic contributions were taken into account, while structural term was omitted as being difficult to estimate precisely. According to Bakker, ${ }^{[20]}$ such structural term should be treated as a rough estimation only even for binary transition metal systems. Third TM alloying element makes it more complex. Nevertheless, the results presented in Figure A1 give us qualitative insight and allow to make a general conclusion, that solid solutions will be energetically preferred in the vast number of compositions throughout the presented phase diagrams. Exceptions can be easily found on the basis of contour maps of differential enthalpy $\Delta H^{\mathrm{am}-\mathrm{ss}}=$ $\Delta H^{\mathrm{am}}-\Delta H^{\mathrm{ss}}$ (Figure A2), where limited number of compositions (for $\mathrm{TM}=\mathrm{Nb}$ in general) with negative sign can be treated as those with higher GFA. Therefore, one should bear in mind that for the majority of 

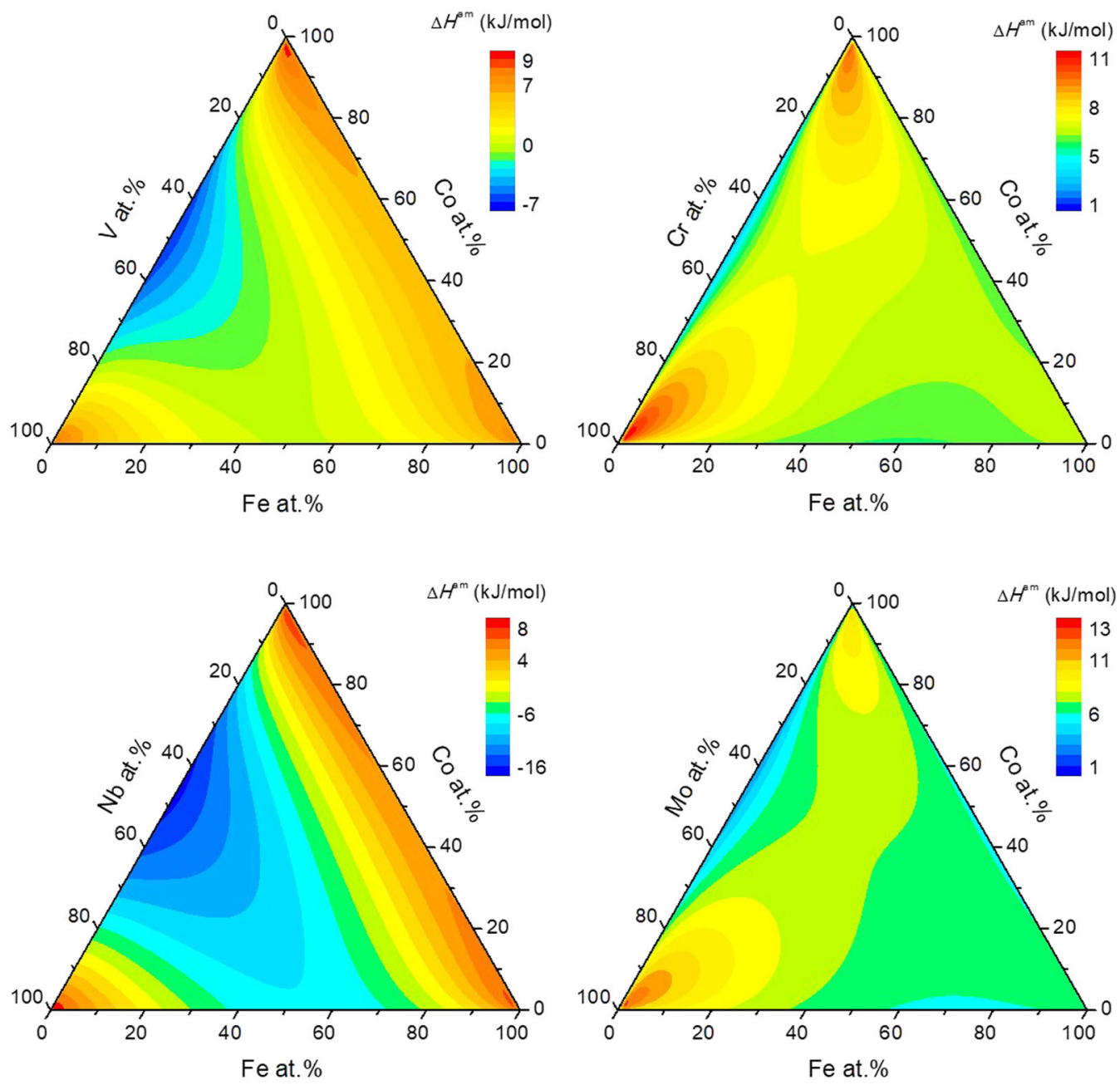

Fig. $1-$ Compositional dependences of formation enthalpies of amorphous phase $\Delta H^{\mathrm{am}}$ of Fe-Co-TM systems $(\mathrm{TM}=\mathrm{V}, \mathrm{Cr}, \mathrm{Nb}, \mathrm{Mo})$.

analyzed alloys specific kinetic conditions will be required to ensure vitrification. Analyzed systems are at most marginal glass formers. Qualitative comparison of $\Delta H^{\mathrm{am}-\mathrm{ss}}$ phase diagrams allows to indicate $\mathrm{Nb}$ as the element of choice, when designing glassy systems and can be helpful in selection of compositions with the highest GFA for each of described Fe-Co-TM systems. Some Fe-Co-Mo alloys take negative values of $\Delta H^{\mathrm{am}-\mathrm{ss}}$, mainly due to positive values of $\Delta H^{\mathrm{ss}}$ in the whole range of compositions.

The composition dependence of normalized mismatch entropy is shown in Figure 2 for Fe-Co-TM (TM $=\mathrm{V}$, $\mathrm{Cr}, \mathrm{Nb}, \mathrm{Mo}$ ) alloys. This particular parameter is governed by atomic radii mismatch between alloy's constituents and the values above 0.1 are reported as characteristic for glass forming alloys. ${ }^{[27]}$ This value was calculated for narrow range of compositions near equiatomic $\mathrm{Co}-\mathrm{Nb}$. For Fe-Co-V and Fe-Co-Mo, normalized mismatch entropy reaches maxima of 0.04 and 0.07 , respectively, for similar range of compositions as the maximum in $\mathrm{Fe}-\mathrm{Co}-\mathrm{Nb}$ system. Atomic radii of $\mathrm{Fe}$ and $\mathrm{Cr}$ takes the same value, therefore $S_{\sigma} / k_{\mathrm{B}}$ changes only with varying $\mathrm{Co}$ content for $\mathrm{Fe}-\mathrm{Co}-\mathrm{Cr}$ alloys. All listed values of normalized mismatch entropy are low due to similar atomic radii of all elements
$\left(r_{\mathrm{Fe}}=0.128 \mathrm{~nm}, \quad r_{\mathrm{Co}}=0.125 \mathrm{~nm}, \quad r_{\mathrm{V}}=0.136 \mathrm{~nm}\right.$, $\left.r_{\mathrm{Cr}}=0.128 \mathrm{~nm}, r_{\mathrm{Nb}}=0.147 \mathrm{~nm}, r_{\mathrm{Mo}}=0.14 \mathrm{~nm}^{[28]}\right)$. The results presented in Figure 2 are in agreement with conclusions drawn from contour maps of formation enthalpy of amorphous phase. One should expect the best GFA for Nb-containing samples, while the driving force for vitrification is much lower for other TM elements.

GFA parameter $\Delta P_{H S}$ combines both, the enthalpy and entropy values, more precisely chemical enthalpy $\Delta H^{\text {chem }}$ and normalized mismatch entropy $S_{\sigma} / k_{\mathrm{B}}$. Compositional dependences of $\Delta P_{H S}$ are shown for all $\mathrm{Fe}-\mathrm{Co}-\mathrm{TM}(\mathrm{TM}=\mathrm{V}, \mathrm{Cr}, \mathrm{Nb}, \mathrm{Mo})$ systems in Figure 3. The more negative $\Delta P_{H S}$ is, the higher GFA is reached for particular composition. The most negative value of glass forming ability parameter vary depending on TM element and equals $\Delta P_{H S}=-0.55$ $\mathrm{kJ} / \mathrm{mol}$ for $\mathrm{Co}_{52} \mathrm{~V}_{48},-0.01 \mathrm{~kJ} / \mathrm{mol}$ for $\mathrm{Co}_{50} \mathrm{Cr}_{50}$, $-3.56 \mathrm{~kJ} / \mathrm{mol}$ for $\mathrm{Co}_{55} \mathrm{Nb}_{45}$, and $-0.35 \mathrm{~kJ} / \mathrm{mol}$ for $\mathrm{Co}_{53} \mathrm{Mo}_{47}$. As can be seen, $\Delta P_{H S}$ reaches minima for Fe-less compositions, as reported previously for Fe-Ni-based alloys. ${ }^{[22]}$ Calculated phase diagrams are similar to contour maps of $\Delta H^{\mathrm{am}}$ and $S_{\sigma} / \mathrm{k}_{\mathrm{B}}$, especially these determined for $\mathrm{V}$ - and $\mathrm{Nb}$-containing systems. The most significant deviations are visible in $\mathrm{Fe}-\mathrm{Co}-\mathrm{Cr}$ 

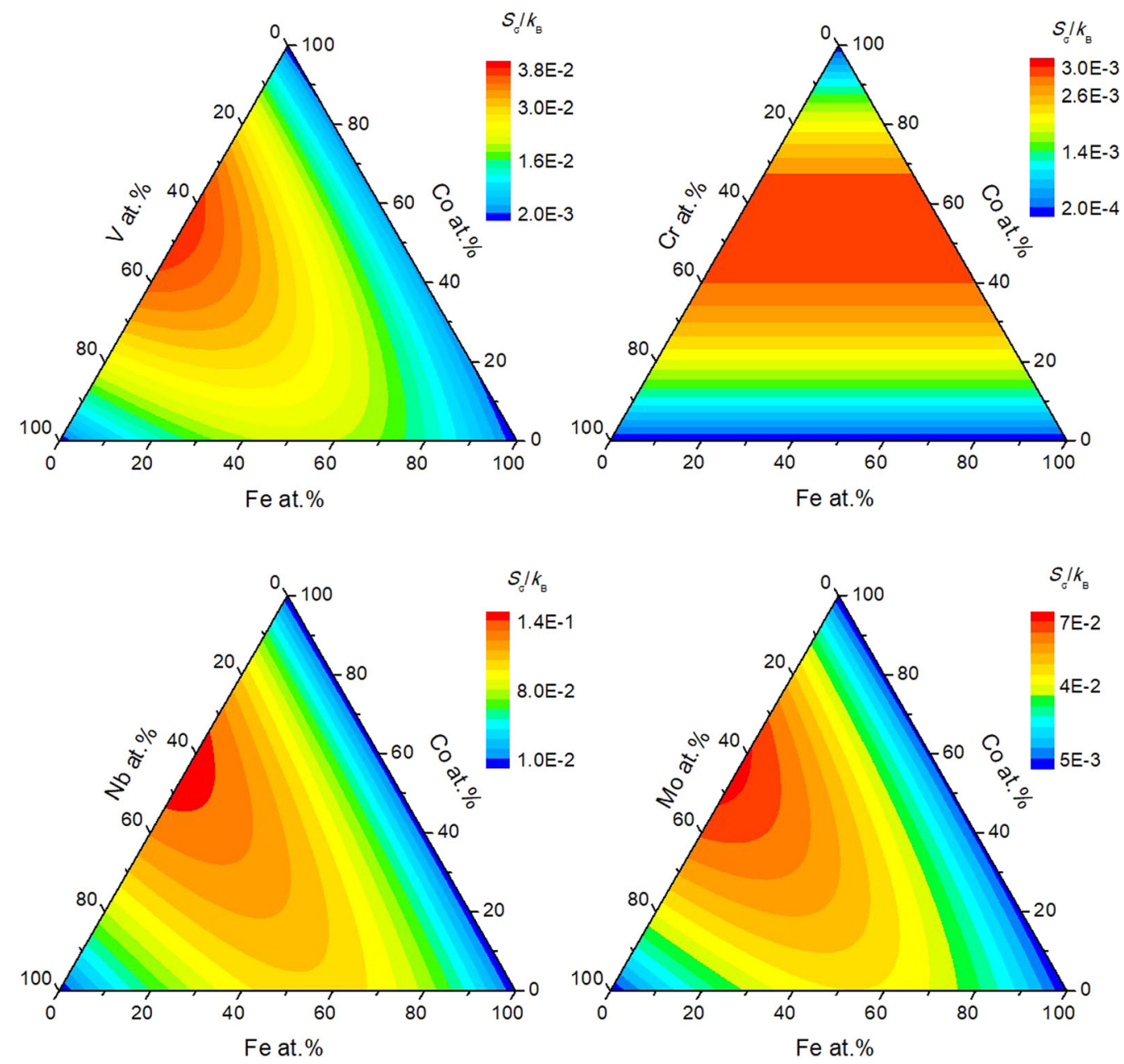

Fig. 2 - Compositional dependences of normalized mismatch entropy $S_{\sigma} / k_{\mathrm{B}}$ calculated for Fe-Co-TM systems $(\mathrm{TM}=\mathrm{V}, \mathrm{Cr}, \mathrm{Nb}, \mathrm{Mo})$.

phase diagrams, mainly due to the equality of atomic radius of $\mathrm{Cr}$ and $\mathrm{Fe}$. All of the presented results are consistent and indicate compositions from $\mathrm{Fe}-\mathrm{Co}-\mathrm{Nb}$ phase diagram as the best glass formers among all systems described herein. Another common trend in presented phase diagrams is the improvement of GFA for vast number of analyzed ternaries with substitution of $\mathrm{Fe}$ by $\mathrm{TM}$ element. Experimental results are in qualitative agreement with obtained phase diagrams as especially $\mathrm{Nb}$, but also $\mathrm{V}$ and Mo are common alloying elements in this group of materials. ${ }^{[29-31]}$ Consistence with the results for $\mathrm{Fe}-\mathrm{Ni}$-based alloys was also underlined throughout the paper. ${ }^{[22]}$ Composition dependences of GFA parameter of pseudobinary $(\mathrm{FeCo})_{100-x} \mathrm{TM}_{x}$ and $(\mathrm{FeNi})_{100-x} \mathrm{TM}_{x}(0 \leq x \leq 100)$ alloys (Figure 4), for clarity reasons with equal content of $\mathrm{Fe}$ and $\mathrm{Co} / \mathrm{Ni}$, are another confirmation of convergence of results for $\mathrm{Ni}$ - and Co-containing systems (data for Ni-containing alloys on the basis of Reference 22). Superiority of $\mathrm{Nb}$ substitution is evident once again. Values of $\Delta P_{H S}$ for $\mathrm{Co}-$ and $\mathrm{Ni}$-containing alloys are similar for the whole range of $x$. Small advantage of $\mathrm{Ni}$ can be at least partially attributed to commonly observed, in calculations based on Miedema's model, overestimation of stability of Ni alloys. ${ }^{[32]}$

Chemical enthalpy dependences of normalized mismatch entropy are shown for all Fe-Co-TM (TM $=\mathrm{V}$, $\mathrm{Cr}, \mathrm{Nb}, \mathrm{Mo}$ ) systems in Figure 5. The stabilization of an amorphous phase against solid solutions and intermetallic compounds can be achieved by an increase in normalized mismatch entropy and a decrease in mixing enthalpy. Most of calculated points (each point reflects single composition) are plotted outside of the trapezoidal area, which has been proposed by Takeuchi and Inoue, ${ }^{[27]}$ and can be defined as a glass forming region. It was determined on empirical way taking into account vast number of experimental data. It can be stated that compositions lying outside the marked region have negligibly low probability to vitrify. All compositions containing $\mathrm{Cr}$ are lying well outside of GFA area, mainly due to low values of $S_{\sigma} / k_{\mathrm{B}}$. V-containing samples are on the verge of fulfillment of GFA criterion. Therefore, in the case of thin films, control of kinetics of synthesis process can allow to avoid crystallization. Niobium can be treated once again as the best substitution among all analyzed $3 d$ and $4 d$ transition metals, as most of 

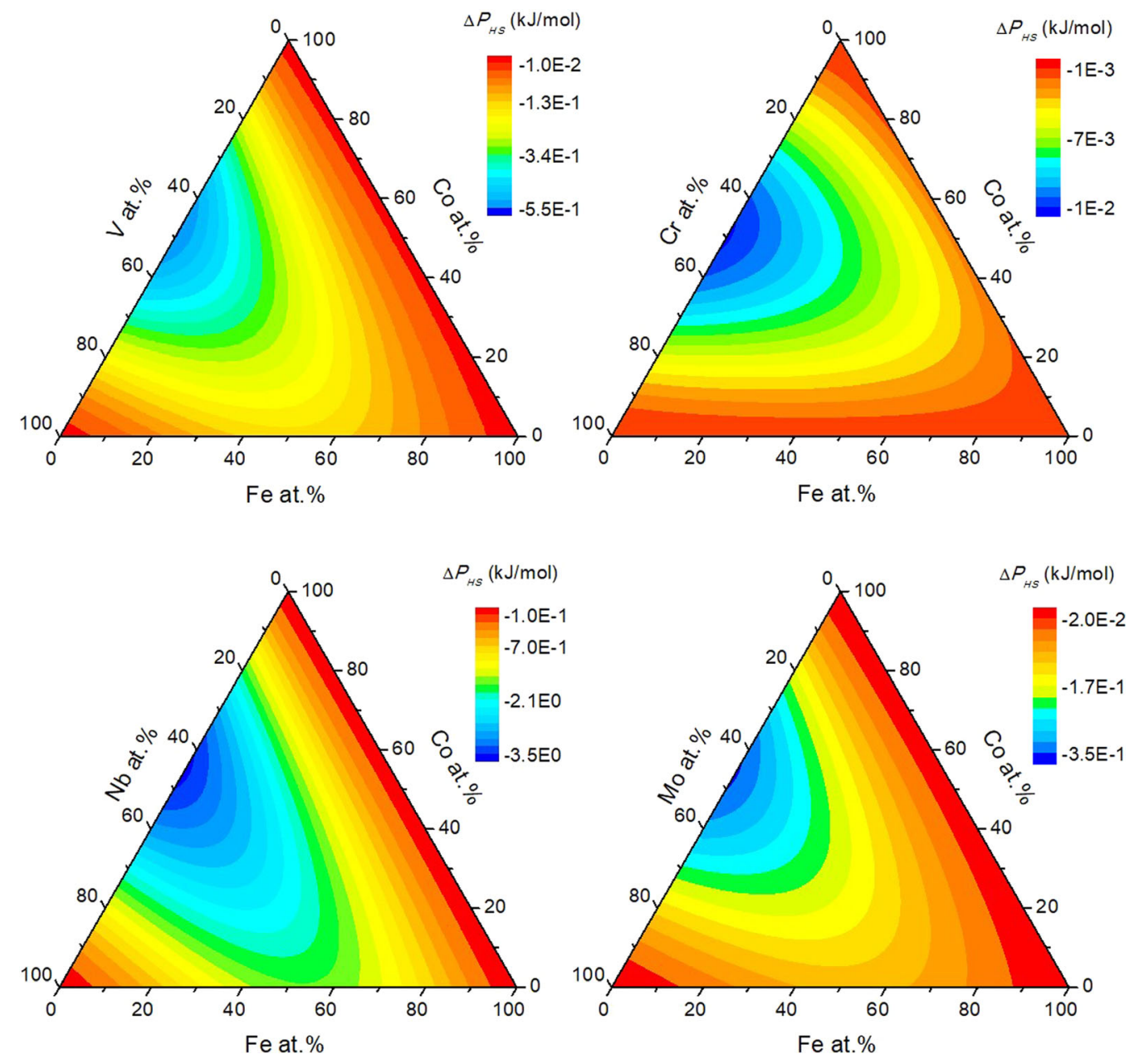

Fig. 3 - Compositional dependences of glass forming ability parameter $\Delta P_{H S}$ calculated for Fe-Co-TM systems $(\mathrm{TM}=\mathrm{V}, \mathrm{Cr}, \mathrm{Nb}, \mathrm{Mo})$.

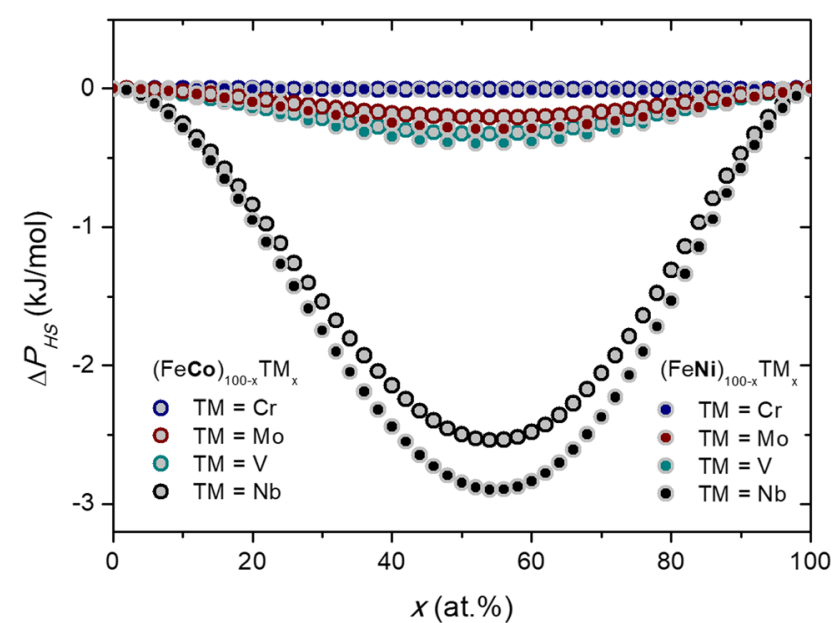

Fig. 4 - Compositional dependences of glass forming ability parameter $\Delta P_{H S}$ calculated for $(\mathrm{FeCo})_{100-x} \mathrm{TM}_{x}(0 \leq x \leq 100$, TM $=\mathrm{V}, \mathrm{Cr}, \mathrm{Nb}, \mathrm{Mo}$ ) alloys. Curves are compared to the values determined for $(\mathrm{FeNi})_{100-x} \mathrm{TM}_{x}$ alloys $(0 \leq x \leq 100, \mathrm{TM}=\mathrm{V}, \mathrm{Cr}$, $\mathrm{Nb}, \mathrm{Mo})^{[22]}$

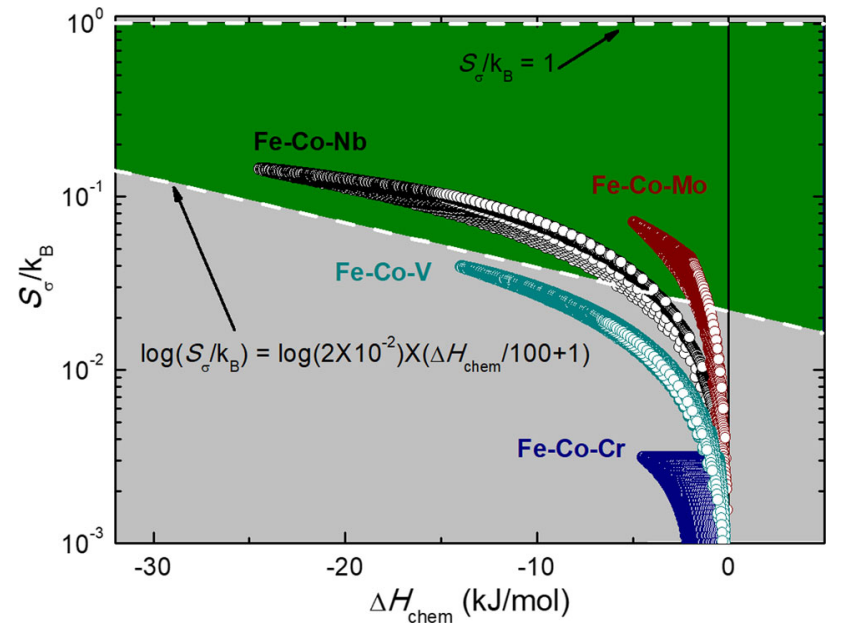

Fig. 5-Relation between $\log \left(S_{\sigma} / k_{\mathrm{B}}\right)$ and $\Delta H^{\text {chem }}$ calculated for $\mathrm{Fe}-\mathrm{Co}-\mathrm{TM}$ systems $(\mathrm{TM}=\mathrm{V}, \mathrm{Cr}, \mathrm{Nb}, \mathrm{Mo})$. 
Fe-Co- $\mathrm{Nb}$ compositions are inscribed in a trapezoidal area.

\section{CONCLUSIONS}

Determined phase diagrams and calculated glass forming abilities of numerous ternary alloys can be used as a key element to design composition of amorphous FeCo-based films with specific structure and morphology. The highest GFA, which can be helpful in synthesis of glassy samples in various states (also as nanoglasses), was reached for $\mathrm{Fe}-\mathrm{Co}-\mathrm{Nb}$ alloys. One can note that the driving force for vitrification can be improved by substitution of $\mathrm{Fe}$ by other transition elements, as GFA parameter $\Delta P_{H S}$ reaches the most negative values for Fe-less compositions. All the conclusions drawn on the basis of phase diagrams obtained for Fe-Co-TM systems (TM $=\mathrm{V}, \mathrm{Cr}, \mathrm{Nb}, \mathrm{Mo}$ ) are consistent with those reported previously for $\mathrm{Fe}-\mathrm{Ni}$-TM alloys. ${ }^{[22]}$
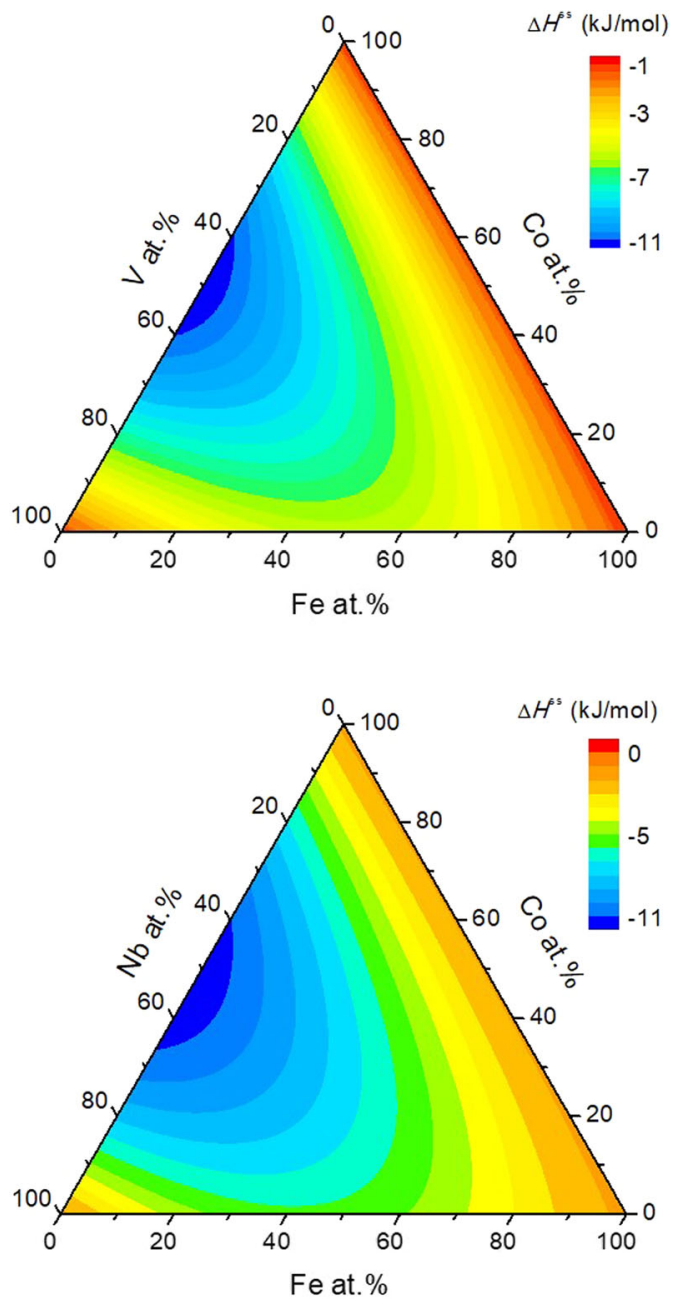

\section{OPEN ACCESS}

This article is licensed under a Creative Commons Attribution 4.0 International License, which permits use, sharing, adaptation, distribution and reproduction in any medium or format, as long as you give appropriate credit to the original author(s) and the source, provide a link to the Creative Commons licence, and indicate if changes were made. The images or other third party material in this article are included in the article's Creative Commons licence, unless indicated otherwise in a credit line to the material. If material is not included in the article's Creative Commons licence and your intended use is not permitted by statutory regulation or exceeds the permitted use, you will need to obtain permission directly from the copyright holder. To view a copy of this licence, visit http://creat ivecommons.org/licenses/by/4.0/.

\section{APPENDIX}

See Figures A1 and A2.
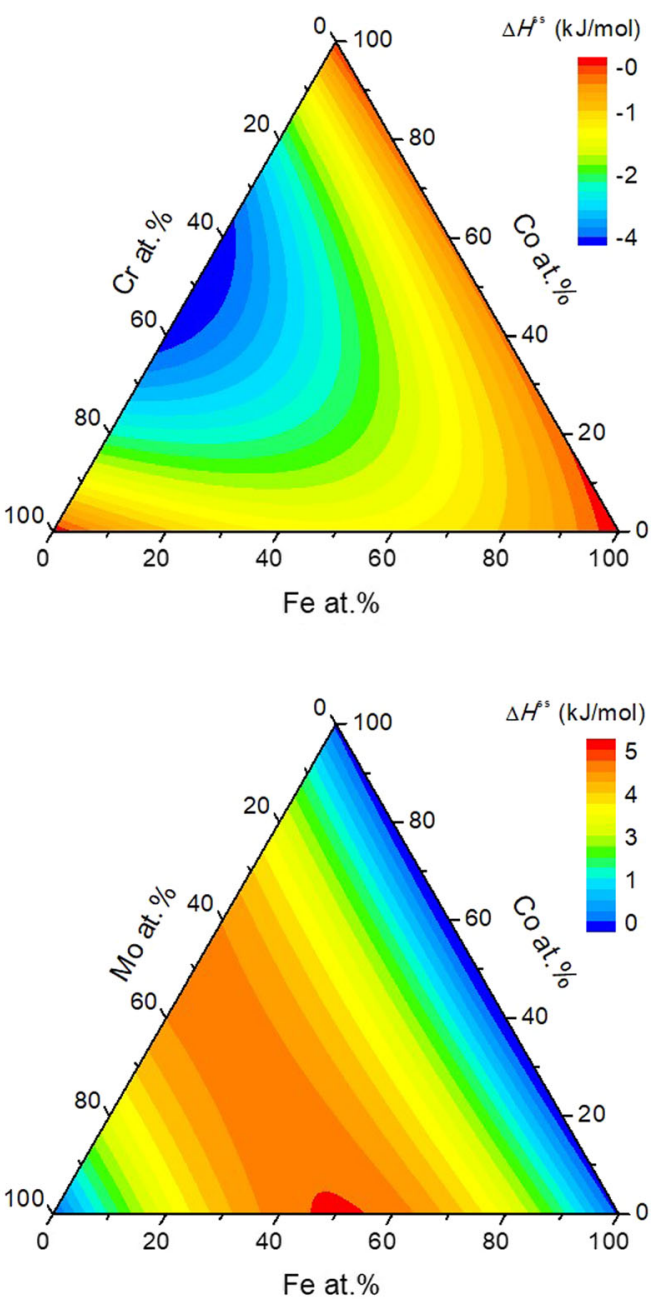

Fig. A1 - Compositional dependences of formation enthalpies of solid solution $\Delta H^{\mathrm{ss}}$ of Fe-Co-TM systems $(\mathrm{TM}=\mathrm{V}, \mathrm{Cr}, \mathrm{Nb}, \mathrm{Mo})$. 

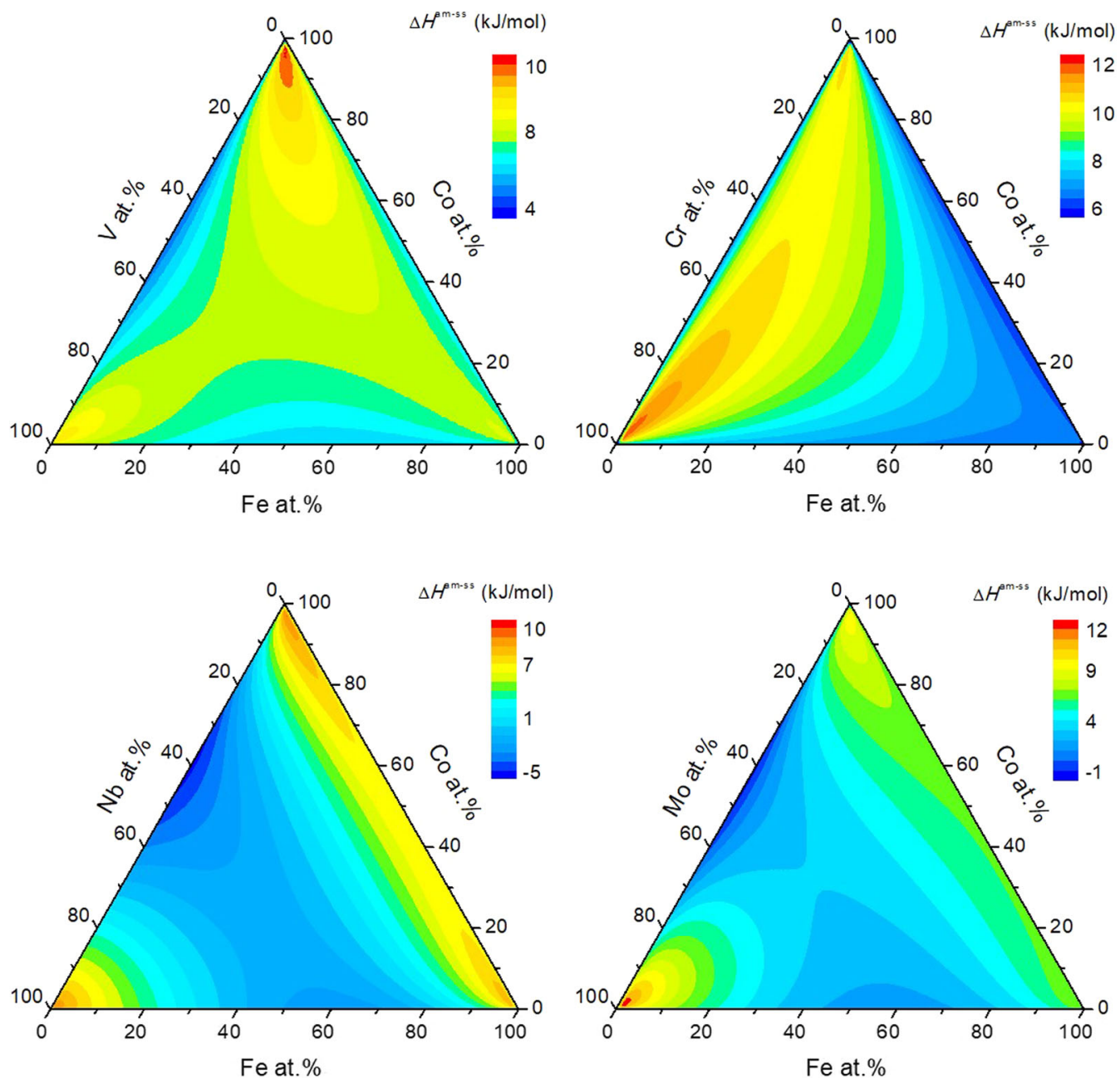

Fig. A2 - Compositional dependences of difference of formation enthalpies of amorphous phase and solid solution $\Delta H^{\text {am-ss }}$ of Fe-Co-TM systems $(\mathrm{TM}=\mathrm{V}, \mathrm{Cr}, \mathrm{Nb}, \mathrm{Mo})$.

\section{REFERENCES}

1. T. Sourmail: Prog. Mater. Sci., 2005, vol. 50, pp. 816-80.

2. R.T. Fingers, R.P. Carr, and Z. Turgut: J. Appl. Phys., 2002, vol. 91 , pp. $7848-50$.

3. A. Inoue, B.L. Shen, and C.T. Chang: Acta Mater., 2004, vol. 52, pp. 4093-99.

4. S. Bhattacharya, E.A. Lass, S.J. Poon, G.J. Shiflet, M. Rawlings, M. Daniil, and M.A. Willard: J. Appl. Phys., 2012, https://doi.org/ $10.1063 / 1.3692389$.

5. Y. Mei Han, Z. Wang, X. Hui Che, X. Gang Chen, W. Run Li, and Y. Li Li: Mater. Sci. Eng. B Solid-State Mater. Adv. Technol., 2009, vol. 156, pp. 57-61.

6. C.L. Platt, M.K. Minor, and T.J. Klemmer: IEEE Trans. Magn., 2001, vol. 37, pp. 2302-04.

7. X. Li, J. Chen, and K. Zhang: Mater. Des., 2009, vol. 30, pp. 2665-69.

8. F. Li, T. Zhang, A. Inoue, S. Guan, and N. Shen: Intermetallics, 2004, vol. 12, pp. 1139-42.

9. A.H. Taghvaei, J. Bednarčik, and J. Eckert: Intermetallics, 2016, vol. 69 , pp. 21-27.

10. A. Corrias, G. Ennas, A. Musinu, G. Marongiu, and G. Paschina: Chem. Mater., 1993, vol. 5, pp. 1722-26.

11. B. Yang, Y. Wu, X. Li, and R. Yu: Nanomaterials, 2018, https:// doi.org/10.3390/nano8030154.

12. M. Ghodsi, H. Ziaiefar, M. Mohammadzaheri, and A. Al-Yahmedi: Energy, 2019, vol. 176, pp. 561-9.

13. S. Martel: J. Nanopart. Res., 2015, https://doi.org/10.1007/s11051014-2734-2.
14. Z. Śniadecki, D. Wang, Y. Ivanisenko, V.S.K. Chakravadhanula, C. Kübel, H. Hahn, and H. Gleiter: Mater. Charact., 2016, vol. 113 , pp. $26-33$.

15. H. Gleiter: Beilstein J. Nanotechnol., 2013, vol. 4, pp. 517-33.

16. S.H. Nandam, Y. Ivanisenko, R. Schwaiger, Z. Śniadecki, X. Mu, D. Wang, R. Chellali, T. Boll, A. Kilmametov, T. Bergfeldt, H. Gleiter, and H. Hahn: Acta Mater., 2017, vol. 136, pp. 181-89.

17. A. Inoue: Acta Mater., 2000, vol. 48, pp. 279-306.

18. J. Bhatt, W. Jiang, X. Junhai, W. Qing, C. Dong, and B.S. Murty: Intermetallics, 2007, vol. 15, pp. 716-21.

19. F.R. De Boer, R. Boom, W.C.M. Mattens, A.R. Miedema, and A.K. Niessen: Cohesion in Metals, vol. 1 of $t$, North Holland, Amsterdam, 1988.

20. H. Bakker: Enthalpies in Alloys: Miedema's Semi-Empirical Model, Materials, Trans Tech Publications Ltd., Zurich, 1998.

21. Z. Sniadecki, J.W. Narojczyk, and B. Idzikowski: Intermetallics, 2012, vol. 26, pp. 72-77.

22. Z. Śniadecki: Metall. Mater. Trans. A Phys. Metall. Mater. Sci., 2020, vol. 51, pp. 4777-85.

23. G.A. Mansoori, N.F. Carnahan, K.E. Starling, and T.W. Leland: J. Chem. Phys., 1971, vol. 54, pp. 1523-25.

24. Y. Ouyang, X. Zhong, Y. Du, Y. Feng, and Y. He: J. Alloys Compd., 2006, vol. 420, pp. 175-81.

25. Y. Ouyang, X. Zhong, Y. Du, Z. Jin, Y. He, and Z. Yuan: $J$. Alloys Compd., 2006, vol. 416, pp. 148-54.

26. K.C. Chou: Calphad, 1995, vol. 19, pp. 315-25.

27. A. Takeuchi and A. Inoue: Trans. Jpn. Inst. Met., 2000, vol. 41, pp. $1372-78$. 
28. Smithells Metals Reference Book, 7th ed., E.A. Brandes, and G. Brook, eds., Smithells Metals Reference Book, 7th ed., Butterworth-Heinemann Ltd., Oxford, 1992.

29. S. Zameer Abbas, F. Ahmad Khalid, and H. Zaigham: J. Non Cryst. Solids, 2017, vol. 457, pp. 86-92.

30. M. Stoica, R. Li, S. Roth, J. Eckert, G. Vaughan, and A.R. Yavari: Metall. Mater. Trans. A Phys. Metall. Mater. Sci., 2011, vol. 42, pp. 1476-80.
31. R. Li, M. Stoica, G. Liu, and J. Eckert: Metall. Mater. Trans. A Phys. Metall. Mater. Sci., 2010, vol. 41, pp. 1640-45.

32. G. Kreiner, A. Kalache, S. Hausdorf, V. Alijani, J.F. Qian, G. Shan, U. Burkhardt, S. Ouardi, and C. Felser: Zeitschrift fur Anorg. und Allg. Chemie, 2014, vol. 640, pp. 738-52.

Publisher's Note Springer Nature remains neutral with regard to jurisdictional claims in published maps and institutional affiliations. 